\section{Estrogen Receptor Status}

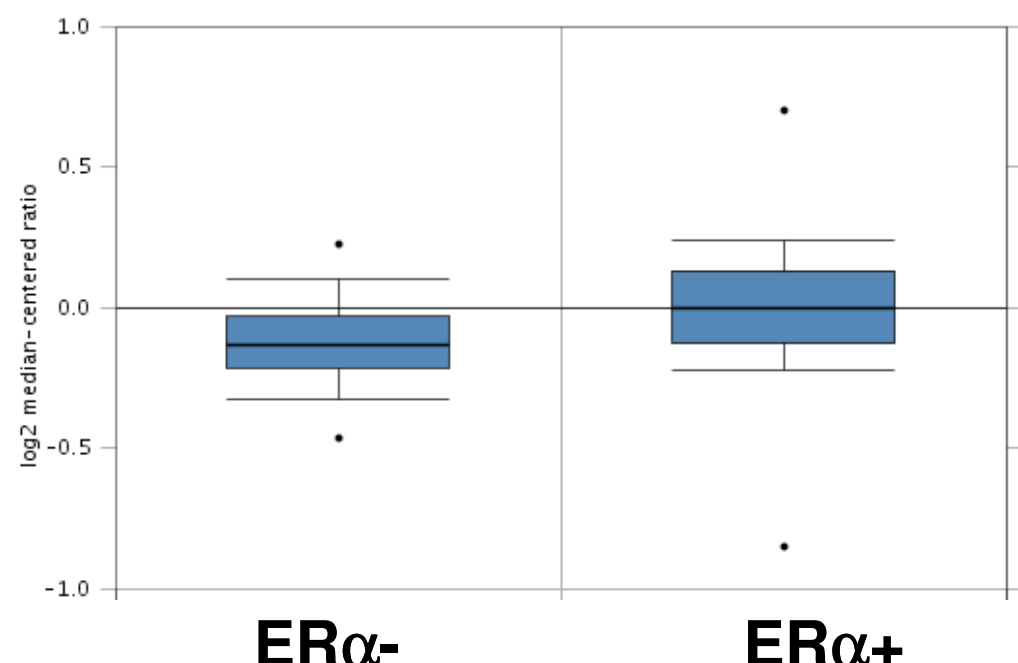

Metastatic Event Status

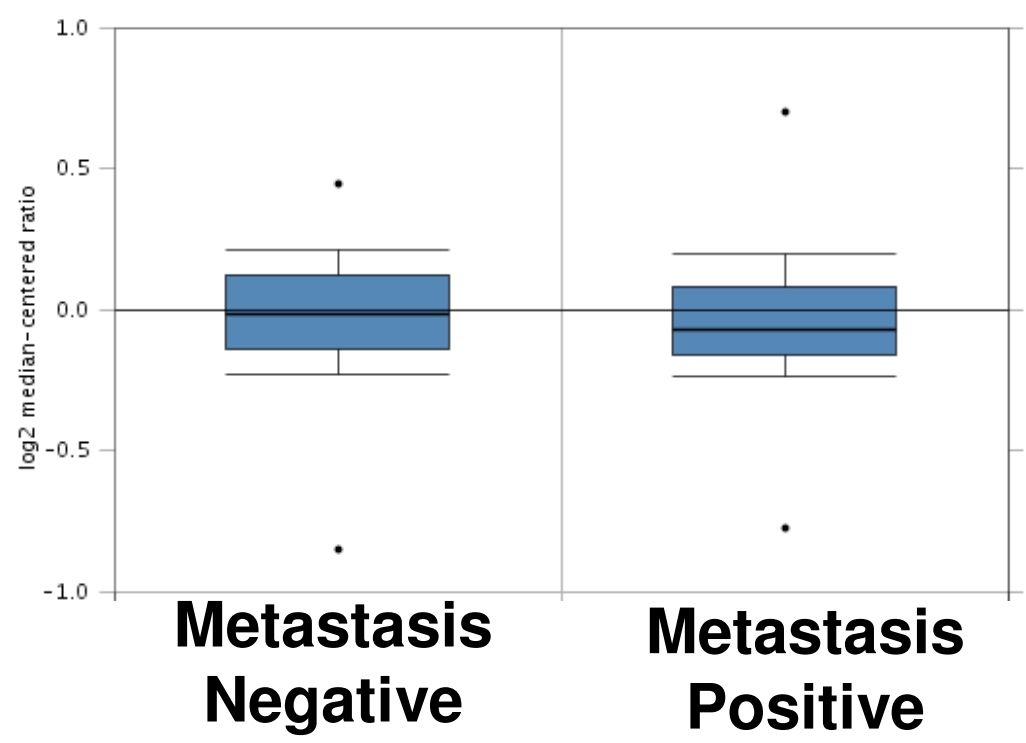

Figure S9: Oncomine examination of NR2F2 expression in breast tumors. Data mining in Oncomine microarray data sets for NR2F2 in breast cancer identified that: A, NR2F2 expression is significantly higher in $E R \alpha+$ breast tumors $(p<0.007)$. B. NR2F2 is significantly lower in metastatic breast tumors $(p<$ 0.05). Data are from (van de Vijver MJ, He YD, van't Veer LJ, et al. A gene-expression signature as a predictor of survival in breast cancer. N Engl J Med 2002; 347: 1999-2009). 